\title{
O Que Move o Preço da Ação? Uma Abordagem sobre a Influência das Notícias no Mercado Acionário ${ }^{1 i}$
}

\section{What Moves Stock Prices? An Approach on the Influence of News on Stock Market}

\author{
César Augusto Tibúrcio Silva \\ Doutor em Controladoria e Contabilidade pela Universidade de São Paulo \\ Professor do Programa Multiinstitucional e Inter-Regional de Pós Graduação em \\ Ciências Contábeis UnB-UFPB-UFRN \\ Endereço: SQS 116 - Bloco A - Ap 402 \\ CEP: 70.386-010 - Brasília/DF - Brasil, e-mail: cesartiburcio@unb.br
} Telefone: (61) 3346-8261

Claudilene Chaves de Carvalho

Especialista em Contabilidade - Universidade de Brasília Endereco: SCLN 409, Bloco E, Bairro: Asa Norte CEP: 70.857-550, Brasilia-DF, Brasil, e-mail: claudileninha@gmail.com

\author{
Danielle Montenegro Salomé Nunes \\ Mestra em Ciências Contábeis \\ Programa Multiinstitucional e Inter-Regional de Pós Graduação em Ciências Contábeis UnB-UFPB-UFRN \\ Professora do Departamento de Ciências Contábeis e Atuariais - Universidade de Brasília \\ Endereço: Prédio da Face, Sala B1-01, Campus Universitário Darcy Ribeiro, Universidade de Brasília \\ CEP 70.910-900, Brasília-DF, Brasil, e-mail: dmontenegro@unb.br
}

RESUMO

Esta pesquisa analisou os dias de negociação da Bolsa de Valores de São Paulo, entre 1990 a 2011, e selecionou as maiores altas e as maiores baixas. A fonte inspiradora foi o trabalho de Cutler et al. (1989). A partir do comportamento dos preços das ações, buscou-se a causa desta variação. Apesar da reduzida variação média diária do índice de ações no período analisado (média de variação diária de $0,29 \%$ ), nota-se que em alguns dias de negociação o mercado acionário apresenta uma elevada volatilidade, com variações significativas nos preços dos ativos. O teste de KS para série mostrou que os dados não podem ser aproximados para uma curva normal em razão da existência de fat tails. A análise empírica mostra que as maiores quedas do mercado acionário brasileiro estão associadas ao plano Collor, a crise política do impeachment do presidente, o plano Real, a crise cambial e a crise do subprime. As maiores altas aconteceram juntamente com o plano Collor, a posse do presidente Itamar, o plano Real, a crise cambial e do subprime. O texto verificou, portanto, que existe uma coincidência temporal nos momentos de maiores quedas e altas na bolsa de valores. Outro aspecto relevante é que nos primeiros anos da amostra nota-se a preponderância dos fatores internos; nos últimos anos, os fatores externos destacam-se, em razão do aumento dos investimentos estrangeiros na Bovespa.

Palavras-chaves: Finanças Comportamentais. Notícias. Mercado Acionário.

\section{ABSTRACT}

This research analyzed the trading days of the Bolsa de Valores de São Paulo (stock exchange of São Paulo), between 1990 to 2011, and selected the highest ups and downs. The inspiration of the project was the work of Cutler et al. (1989). Verifying the behavior of stock prices, we searched the cause of this variation. Despite the small variation of the average daily stock index on the period analyzed (mean daily variation of 0.29\%), it can be noticed that in some trading days the stock market is highly volatile, with significant variations in asset prices. The KS test for series showed that the data cannot be approximated to a normal curve because of the fat tails. The empirical analysis shows that the highest decrease in the Brazilian stock market are associated with the Collor Plan, the president impeachment political crisis, the Real plan, the currency crisis and the subprime crisis. The largest increases occurred with the Collor Plan, the inauguration of President Itamar, the Real plan, the currency crisis and subprime. It was noticed that there is a temporal coincidence in times of high and further drops in the stock market. Another important aspect is that in the early years of the sample it was observed the preponderance of internal factors, in recent years, external factors stand out, due to the increase of the foreign investment in Bovespa.

Key words: Behavioral Finance. News. Stock Market.

\footnotetext{
${ }^{1}$ Artigo recebido em 26.03.2012. Revisado por pares em 25.05.2012 (blind review). Reformulado em 26.06.2012. Recomendado para publicação em 01.07.2012 por José Ribamar Marques de Carvalho (Editor Científico). Publicado em 09.08.2012.
} 


\section{INTRODUÇÃO}

O mercado de ações é movido por informações, sejam quantitativas e/ou qualitativas, relativas às companhias, aos agregados setoriais e macroeconômicos. Elas são utilizadas para avaliar o desempenho de uma ação ou do mercado como um todo. E podem ser interpretadas de inúmeras formas, resultando em comportamentos diferenciados. Uma parte destas informações é regulamentada cuidadosamente pela CVM - Comissão de Valores Mobiliários, tendo por objetivo evitar "privilégios". Uma das principais regras para a comunidade dos investidores é que todos recebam as mesmas informações, ao mesmo tempo.

A variação no comportamento em razão de uma informação irá provocar movimentações nos preços dos ativos transacionados na bolsa de valores. Assim, existe um vínculo entre a existência de uma nova informação e a variação nos preços das ações. Diversos trabalhos já foram realizados usando uma técnica denomina estudo de eventos, onde parte-se de um evento específico, em geral uma informação nova, e tentase medir a influência desse evento sobre os preços dos ativos ${ }^{\text {ii }}$. Esta pesquisa caminha no sentido oposto: a partir de variações no comportamento dos preços das ações, tentase buscar a causa desta variação. Neste sentido, a pesquisa tem como fonte inspiradora o texto de Cutler et al. (1989), denominado What moves stock prices? Este texto foi publicado em 1989 e, segundo o Google Scholar, foi citado mais de setecentas vezes na literatura acadêmica.

Ao analisar uma série temporal do mercado acionário brasileiro é notório seu comportamento oscilante, intercalando momentos de crescimento e períodos de crise. Em geral o mercado apresenta pequenas variações médias diárias. No período de 1989 a 2011 a variação média diária do mercado brasileiro, mensurado pelo Ibovespa, foi de $0,29 \%$. No mesmo período, ocorreram variações diárias entre $30 \%$ (no dia 4 de fevereiro de 1991) e -25\% (dia 21 de março de 1990).

Isto mostra que os índices são instáveis: ora sobe, ora desce. Este movimento pode ser decorrente dos resultados das empresas, mas também de fatores externos, como os relacionados com a economia do país (desemprego, inflação e as taxas de juros, entre outros) e a economia mundial.

Segundo Cutler et al. (1989) a variação do mercado acionário reflete as notícias que ocorrem no mundo financeiro e econômico. Assim, quando uma empresa divulga um resultado inesperado, isto irá refletir na variação acima do normal dos preços das suas ações. De igual forma, uma notícia econômica relevante, como um conjunto de medidas econômicas por parte do governo, também pode afetar o comportamento do mercado acionário.

Em uma averiguação mais detalhada, Cutler et al. (1989) percebeu que as flutuações nos preços de ações e mudanças nos valores fundamentais de ativos são atribuídas a uma série de fatores, sendo um deles a informação, comprovando que os preços das ações reagem a anúncios sobre controle corporativo, à política de regulamentação e as condições macroeconômicas. Entretanto, a aparente ausência de notícias econômicas não inibe os movimentos de ações de mercado.

Este artigo explora o impacto das notícias, em especial de cunho político/econômico, em alguns momentos da história do mercado financeiro brasileiro. Apesar da reduzida variação média diária do índice de ações, conforme indicado 
anteriormente, nota-se que em alguns dias de negociação o mercado acionário apresenta uma elevada volatilidade, com variações significativas nos preços dos ativos. Assim, após selecionar os dias de maior volatilidade do índice do mercado acionário brasileiro, procura-se associar este comportamento com o ambiente econômico.

Diante do exposto, a finalidade é responder a seguinte questão de pesquisa: $O$ que pode ser associado ao comportamento do mercado acionário brasileiro nos momentos de elevada volatilidade? Diante disto, o objetivo da pesquisa é identificar os fatos econômicos e políticos responsáveis pelos momentos de maior volatilidade do mercado acionário brasileiro.

Este trabalho é composto por cinco partes: inicia-se com esta introdução, que reflete o objetivo e o problema estudado, o referencial teórico é a segunda parte, mostrando a base bibliográfica analisada, em seguida na terceira parte encontra-se a método de pesquisa aplicado no estudo, a quarta parte retrata a análise dos resultados, obtidos por meio da investigação dos dados colhidos, seguidos das considerações finais exibidas na última parte do artigo.

\section{REFERENCIAL TEÓRICO}

\subsection{Finanças Comportamentais}

De acordo com Thaler e Mullainathan (2000), as Finanças Comportamentais estudam como a combinação de conceitos econômicos, sociológicos e psicológicos pode explicar o que acontece na vida econômica real, em que os agentes econômicos apresentam limitações ao exercício da plena racionalidade. A teoria tradicional de finanças comportamentais, defende a existência de agentes com capacidade de tomar decisões de acordo com a racionalidade ilimitada; em termos teóricos, isto significa, tomar decisões segundo a teoria de utilidade esperada, formando expectativas nãoviesadas sobre eventos futuros.

Hirshleifer (2001) e Shleifer (2001), entre outros, citam vários exemplos de racionalidade limitada nos mercados financeiros. Estudos empíricos experimentais realizados na área de finanças comportamentais mostram que existem situações em que o comportamento de agentes nos mercados financeiros se desvia da racionalidade proposta por modelos neoclássicos Milanez (2003). Assim, investidores exageram nas boas notícias, além de não aceitarem perdas, relutando em liquidar suas posições em razão de queda no mercado financeiro.

$\mathrm{Na}$ procura por razões que explicam a movimentação do mercado acionário percebe-se que existe uma confiança por parte dos investidores nas informações. Estes acreditam que existe uma maior probabilidade em obter lucros nas suas aplicações baseando-se em informações, quando não é necessariamente isso que ocorre. Assim, as notícias têm o poder de afetar o julgamento das pessoas, provocando excessos de otimismo e de pessimismo, que por sua vez podem gerar o que se denomina de bolhas e pânico no mercado. Isso acontece simplesmente porque as pessoas tendem a acreditar que é possível prever resultados futuros causando uma anomalia conhecida como excesso de otimismo ou excesso de confiança. 


\subsection{A influência da notícia sobre o preço da ação.}

Segundo Cutler et al. (1989), as notícias, mesmo aquelas relacionadas com a economia, refletem os movimentos e preços das ações. A influência dos acontecimentos políticos e econômicos afeta diretamente a movimentação das bolsas de valores do mundo todo. Os autores afirmam que notícias macroeconômicas tem grande efeito sobre os preços das ações e é evidente a forte relação em diferentes estágios do ciclo de negócios.

Esta relação é causada pelo efeito na taxa de desconto em relação ao fluxo de caixa esperados. Dependendo do setor o preço é influenciado diretamente, como no caso de condições climáticas desfavoráveis para o cultivo de uma determinada matéria prima que tem seus ativos negociados na bolsa de valores. Este é o caso da pesquisa de Roll (1984), que analisou diversos fatores que influenciam a formação do preço de suco de laranja no mercado futuro dos Estados Unidos. Os resultados mostram uma correlação significativa entre o preço do suco de laranja no mercado futuro e a previsão das alterações climáticas na região do cultivo, inclusive variações de preços decorrentes de previsões meteorológicas erradas. Segundo Roll (1984) isto chega a sugerir que o preço do mercado futuro do suco está respondendo às previsões do Serviço Nacional de Meteorologia, pois em nenhum momento foi encontrada uma relação entre $o$ comportamento do mercado e as chuvas.

Fama e French (1986), assim como CPS (1989) dentre outros, mostram a existência de significativa correlação entre retornos diários (retornos positivos seguidos por retornos negativos). Os defensores da teoria da Hipótese dos Mercados Eficientes (HME), admitem que no mínimo parcialmente as ações estão sujeitas a previsibilidade de seus retornos, baseando-se na análise de retornos passados.

Em um mundo de agentes racionais, os preços só deveriam mudar com a chegada de novas informações. Entretanto, na prática, os preços se movimentam e não podem ser atribuídos necessariamente a qualquer nova informação, uma vez que "flutuações de preços tendem a ser grandes demais para serem justificadas pelas novas informações que chegam ao conhecimento dos investidores" (SHILLER, 1981).

\section{MÉTODO DE PESQUISA}

A presente pesquisa foi realizada por meio de uma abordagem quantitativa, documental, utilizando referências bibliográficas com fundamentos teóricos e específicos, artigos, boletins informativos, artigos científicos publicados em sites acadêmicos relacionados ao Mercado Capitais e ainda a análise de 5.487 registros diários de preço de fechamento do Ibovespa extraídos do site da BM\&F.

\subsection{Dos Índices}

Cada ação tem um comportamento diferenciado na bolsa de valores, a soma desse comportamento resulta nos mais de vinte índices existente na Bovespa.

O índice mais importante que reflete o comportamento do mercado acionário brasileiro é o Ibovespa, que existe desde 1968. O Índice Ibovespa corresponde ao 
somatório dos pesos (quantidade teórica da ação multiplicada pelo último preço da mesma) das ações integrantes da sua carteira teórica. Assim, é apurado por meio da fórmula:

$$
\text { Ibovespa }_{t}=\sum_{\mathrm{i}=1} P i, t^{*} Q i, t
$$

Onde:

Ibovespa $t=$ Índice Bovespa no instante $t$

$N=$ número total de ações componentes da carteira teórica;

$P=$ último preço da ação " $i$ " no instante $t$;

$Q=$ quantidade teórica da ação " $i$ " na carteira no instante $t$.

O período de tempo analisado refere-se as variações diárias entre 29 de dezembro de 1989 a 21 de dezembro de 2011. A partir desta série histórica selecionaram-se trinta movimentações diárias correspondendo aos quinze maiores aumentos e as quinze maiores reduções ocorridos com o Ibovespa durante o período. É importante salientar que durante o período analisado por diversas vezes o número índice do Ibovespa foi dividido por dez. A série histórica considerada ajusta os valores para estes casos.

Para encontrar as trinta datas analisadas inicialmente calculou-se a variação diária a partir da seguinte expressão:

Variação $=$ Ln $\left(\right.$ Ibovespa $_{\mathrm{t}} /$ Ibovespa $\left._{\mathrm{t}-1}\right)$

Sendo $\ln =$ logaritmo neperiano. Após a identificação dos dias de negociação onde ocorreram as variações mais extremas, buscou-se associar esta variação com as notícias, agora fatos históricos, ocorridas no Brasil no período da série analisada.

\section{APRESENTAÇÃO E DISCUSSÃO DOS RESULTADOS}

\subsection{Comportamento do Índice no Tempo}

O gráfico 1 apresenta a evolução da bolsa de valores, considerando a data de 29 de dezembro de 1989 como sendo igual a 100. Estão em destaques no gráfico alguns momentos onde o mercado atinge um ponto máximo (agosto de 1994, julho de 1997, fevereiro de 2000 e maio de 2008) e três momentos de baixa (setembro de 1998, julho de 2002 e novembro de 2008). Os momentos de baixa estão relacionados com a crise cambial brasileira, a incerteza eleitoral e a crise financeira mundial.

Figura 1 - Evolução do Ibovespa em Número índice - 1990 a 2011 


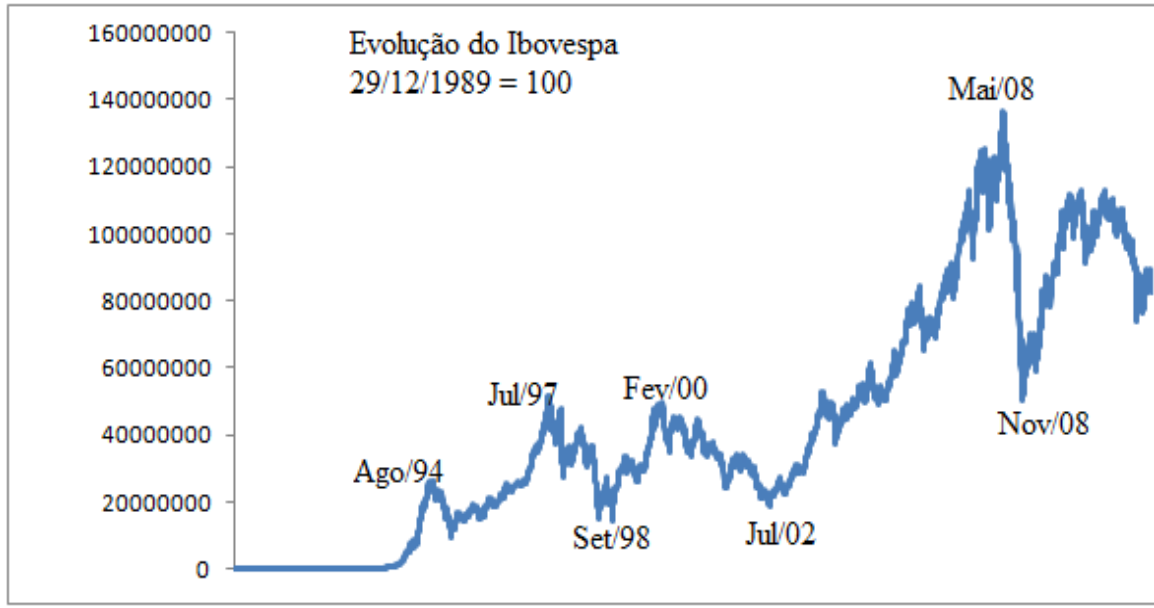

Fonte: Dados da Pesquisa, 2011

O gráfico 2 mostra a mesma evolução, em idêntico período, mas o número índice é transformado em escala logaritmo. É possível perceber que as grandes taxas de crescimento da bolsa de valores efetivamente ocorreram antes de 1994. Isto já era esperado, uma vez que neste momento o elevado patamar inflacionário fazia com que as variações diárias da bolsa fossem superiores, em média, aquelas ocorridas no período posterior.

Figura 2 - Evolução do Ibovespa em Escala Logaritma - 1990 a 2011

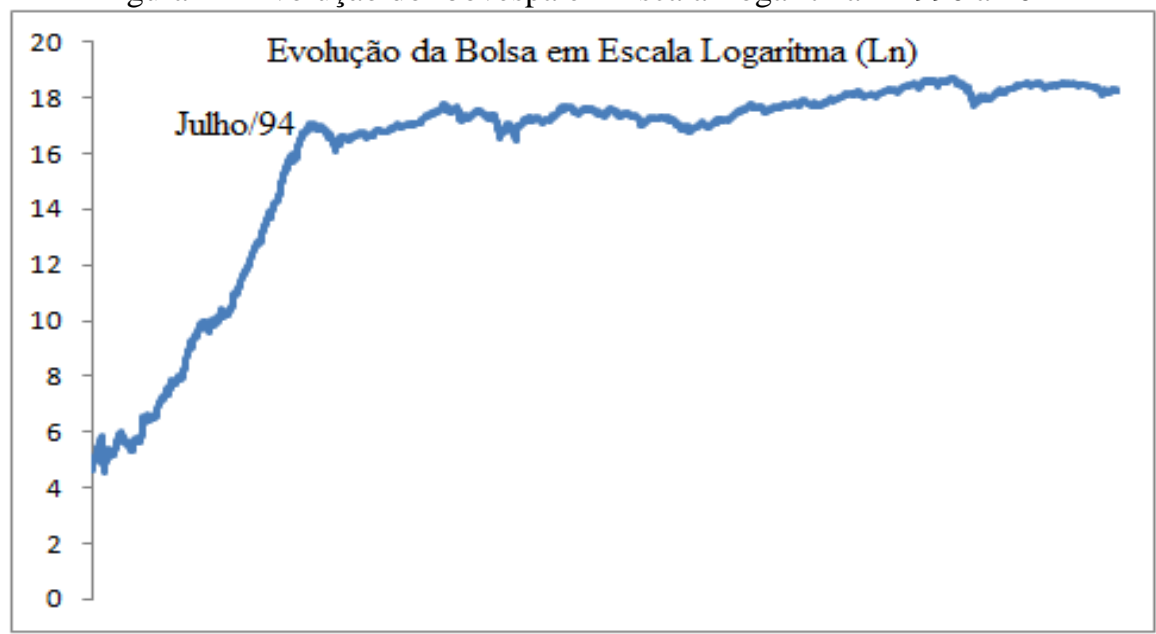

Fonte: Dados da Pesquisa, 2011

A figura 3 apresenta a variação diária do Ibovespa para a série histórica estudada. Observa-se a alta volatilidade do mercado acionário brasileiro, em particular nos primeiros anos da série. A volatilidade pode ser descrita como uma medida de dispersão dos retornos de um título ou índice de mercado. Quanto mais o preço de uma ação varia num período curto de tempo, maior o risco de se ganhar ou perder dinheiro negociando esta ação. Por este motivo a volatilidade é uma medida de risco. A volatilidade é a quantidade e intensidade de flutuações e oscilações que ocorrem com uma série de retornos. Estas flutuações relacionam-se com a média dos retornos.

A figura 3 destaca quatro momentos específicos: o início da série, quando o país tentava reduzir as taxas inflacionárias com pacotes econômicos, a criação do Plano 
Real, a crise cambial brasileira e a crise financeira mundial. É possível perceber que a intensidade das variações diárias da bolsa de valores reduziu-se no tempo.

Figura 3 - Variação Diária do Ibovespa - 1990 a 2011

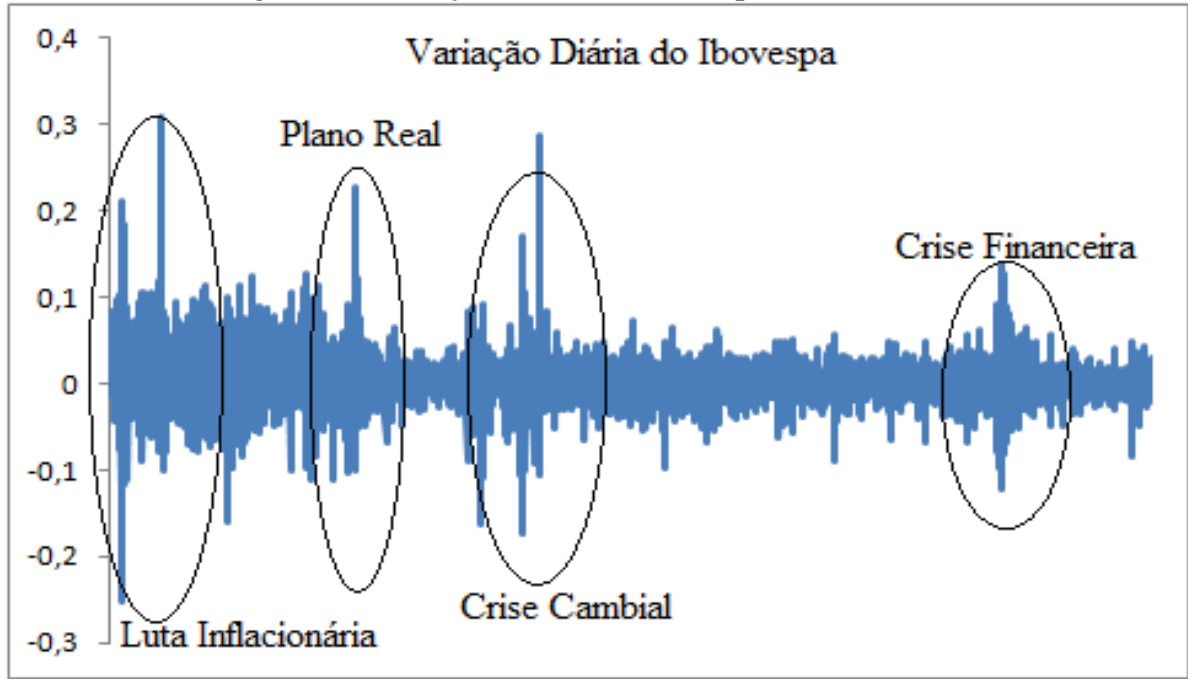

Fonte: Dados da Pesquisa, 2011.

\subsection{Estatísticas Descritivas e Normalidade da Série}

A Tabela 1 apresenta as estatísticas descritivas da série analisada. Em média a bolsa de valores apresentou uma evolução diária de 0,29\%, com mediana de 0,19\%. A assimetria foi de 0,422 ; numa curva normal a assimetria é zero. $\mathrm{O}$ valor obtido indica uma assimetria positiva, a direita da curva. A curtose foi de 8,997 , sendo que numa distribuição normal o valor seria zero. $\mathrm{O}$ valor da curtose indica uma curva achatada, com grandes valores na cauda. Isto é coerente com a noção de Taleb (2007), que no seu livro A Lógica do Cisne Negro insiste que a distribuição dos dados da variação do mercado acionário apresenta muitas caudas longas (fat tails). É também interessante observar que o primeiro quartil é negativo. Isto significa dizer que no mínimo em $25 \%$ do período analisado a bolsa de valores operou em baixa.

\begin{tabular}{lr}
\multicolumn{2}{c}{ Tabela 1 - Estatística Descritiva } \\
\cline { 2 - 2 } Estatística & \multicolumn{1}{c}{ Valor } \\
\hline Média &, 0029 \\
Mediana &, 0019 \\
Desvio-padrão &, 02955 \\
Assimetria &, 422 \\
Curtose & 8,997 \\
1o. Quartil &,- 0112 \\
3o. Quartil &, 0160 \\
N & 5485 \\
Fonte: Dados da Pesquisa, 2011.
\end{tabular}

Do mesmo modo testou-se a distribuição poderia ser aproximada por uma curva normal. O teste KS foi utilizado e o valor obtido foi de 5,987, com significância de 0,000. Isto significa que a distribuição não pode ser aproximada por uma normal, 
conforme pode ser visualizada na figura 4. A assimetria à direita e a curtose são evidenciadas na figura através da existência de observações no lado direito, correspondendo a uma cauda longa (fat tail).

Figura 4 - Distribuição de Frequência da Variação Diária do Ibovespa - 1990 a 2011

Distribuição de Frequência

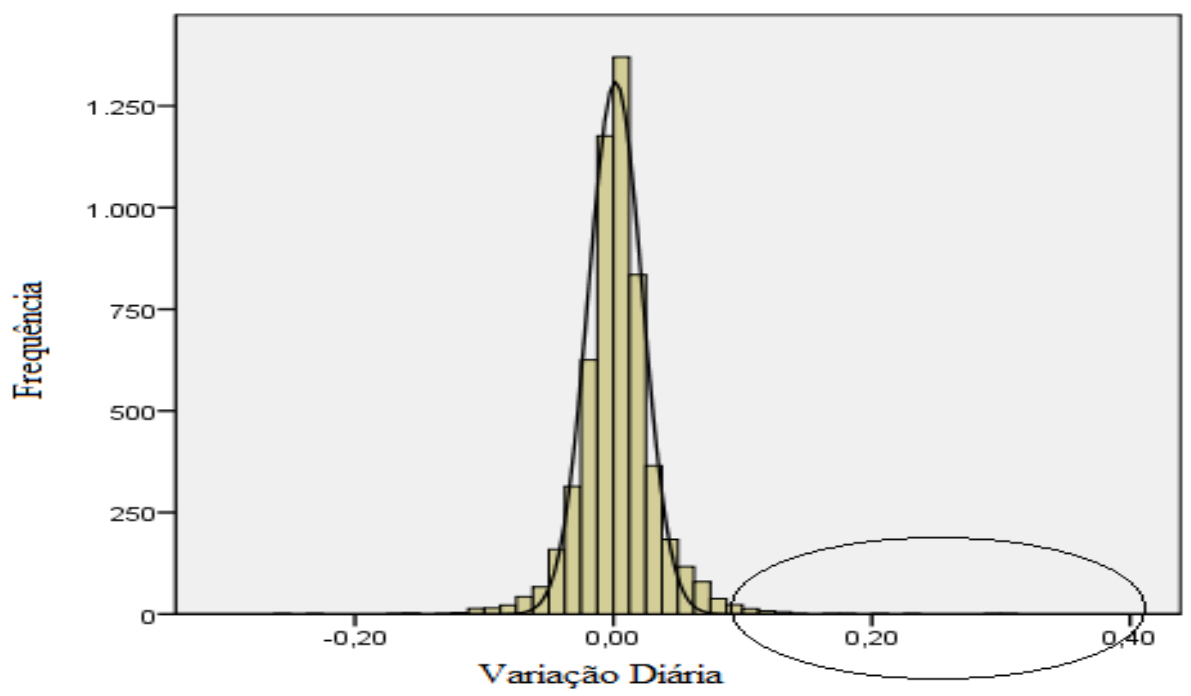

Fonte: Dados da Pesquisa, 2011.

\subsection{Fatos históricos e as flutuações do mercado acionário}

A partir da série histórica coletaram-se as maiores variações ocorridas no mercado acionário brasileiro. Inicialmente apresentam-se as maiores baixas do mercado no período analisado. A tabela 2 mostra as quinze maiores baixas do mercado no período. Destas baixas, seis dizem respeito a um momento específico da história brasileira: o Plano Collor, onde o governo decretou o congelamento dos ativos financeiros. Isto reduziu a liquidez da economia, mas "desapareceu" com o dinheiro dos investidores. A consequência foi a queda do mercado acionário. Após esta série de eventos destaca-se a crise que antecede a desvalorização do real, em 1998, quando o governo brasileiro recebeu auxílio do FMI.

Tabela 2 - As maiores baixas do mercado acionário - 1990 a 2011 


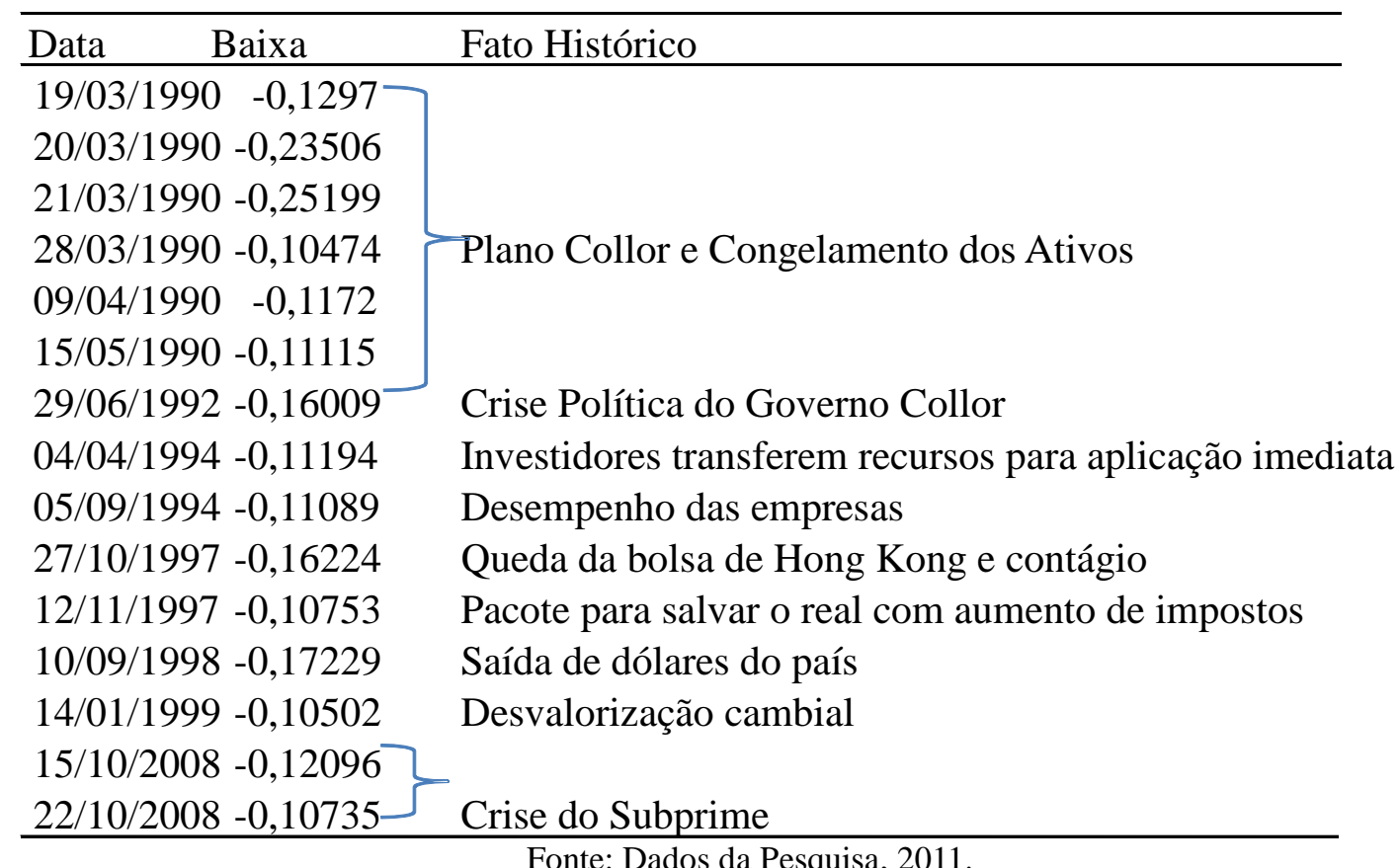

A figura 5 mostra baixas de maneira mais didática, ao longo do tempo. É possível perceber um aumento no espaço temporal entre as crises. Os três primeiros momentos destacados na figura estão próximos em termos temporais: o Plano Collor, a Crise Política e o Plano Real. Um espaço de tempo existe entre a criação da nova moeda e a crise cambial, que ocorre entre 1998 e 1999. Após isto, a crise do subprime ocorre quase dez anos depois. É importante destacar que dos cinco fatos destacados no gráfico, quatro são econômicos, sendo três deles de origem interna. Somente um é político: a crise do governo Collor que conduziu a cassação do mandato do então presidente.

Figura 5 - As maiores baixas do mercado acionário

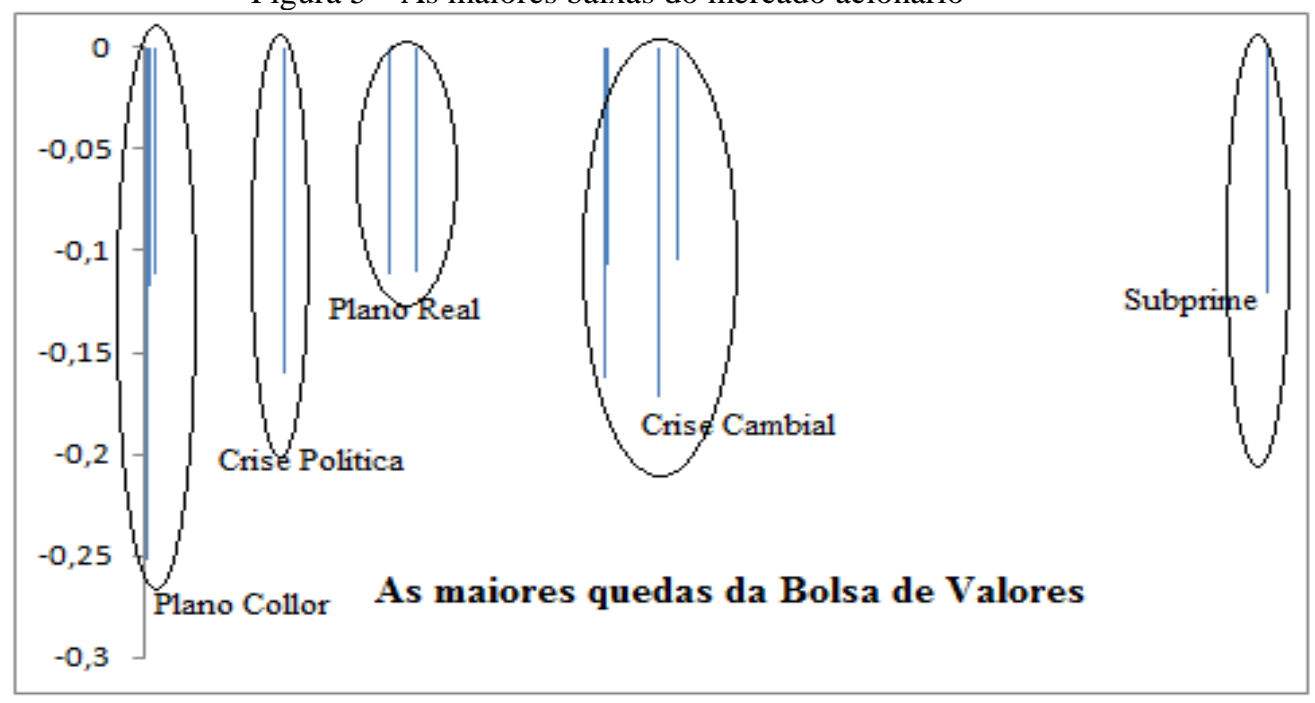

Fonte: Dados da Pesquisa, 2011. 
Também selecionou-se os maiores aumentos no mercado acionário no período. Das quinze datas, cinco estão relacionadas com o Plano Collor e quatro com o processo de implantação do Plano Real, conforme apresentado na Tabela 3.

Tabela 3 - Os Maiores Aumentos do Mercado Acionário- 1990 a 2011

\begin{tabular}{|c|c|c|}
\hline Data & Aumentos & Fato Histórico \\
\hline 03/04/1990 & 0,210961 & \\
\hline 05/04/1990 & 0,140385 & \\
\hline 17/04/1990 & 0,185036 & Plano Collor \\
\hline 17/01/1991 & 0,119299 & \\
\hline 04/02/1991 & 0,307921 & \\
\hline 23/12/1992 & 0,125437 & Cresce a popularidade de Itamar \\
\hline $19 / 05 / 1994$ & 0,11462 & \\
\hline $23 / 02 / 1995$ & 0,11346 & \\
\hline $10 / 03 / 1995$ & 0,228126 & Plano Real \\
\hline $14 / 03 / 1995$ & 0,121852 & \\
\hline $11 / 09 / 1998$ & 0,125781 & Ajuda Externa do FMI \\
\hline $15 / 09 / 1998$ & 0,171289 & \\
\hline 15/01/1999 & 0,288176 & Desvalorização Cambial \\
\hline $13 / 10 / 2008$ & 0,136794 & Desdobramento da Crise Financeira \\
\hline 28/10/2008 & 0,125952 & \\
\hline
\end{tabular}

A figura 6 mostra estes eventos ao longo do tempo. É possível notar que existem cinco momentos distintos de crescimento abrupto do mercado: a crise do Plano Collor, a popularidade do início do governo Itamar, o Plano Real, a Crise Cambial e a Crise do Subprime. Destes eventos, quatro são econômicos, sendo três deles internos e um externo. Somente um deles pode ser considerado tipicamente político.

Figura 6 - As Maiores Altas da Bolsa de Valores - 1990 a 2011

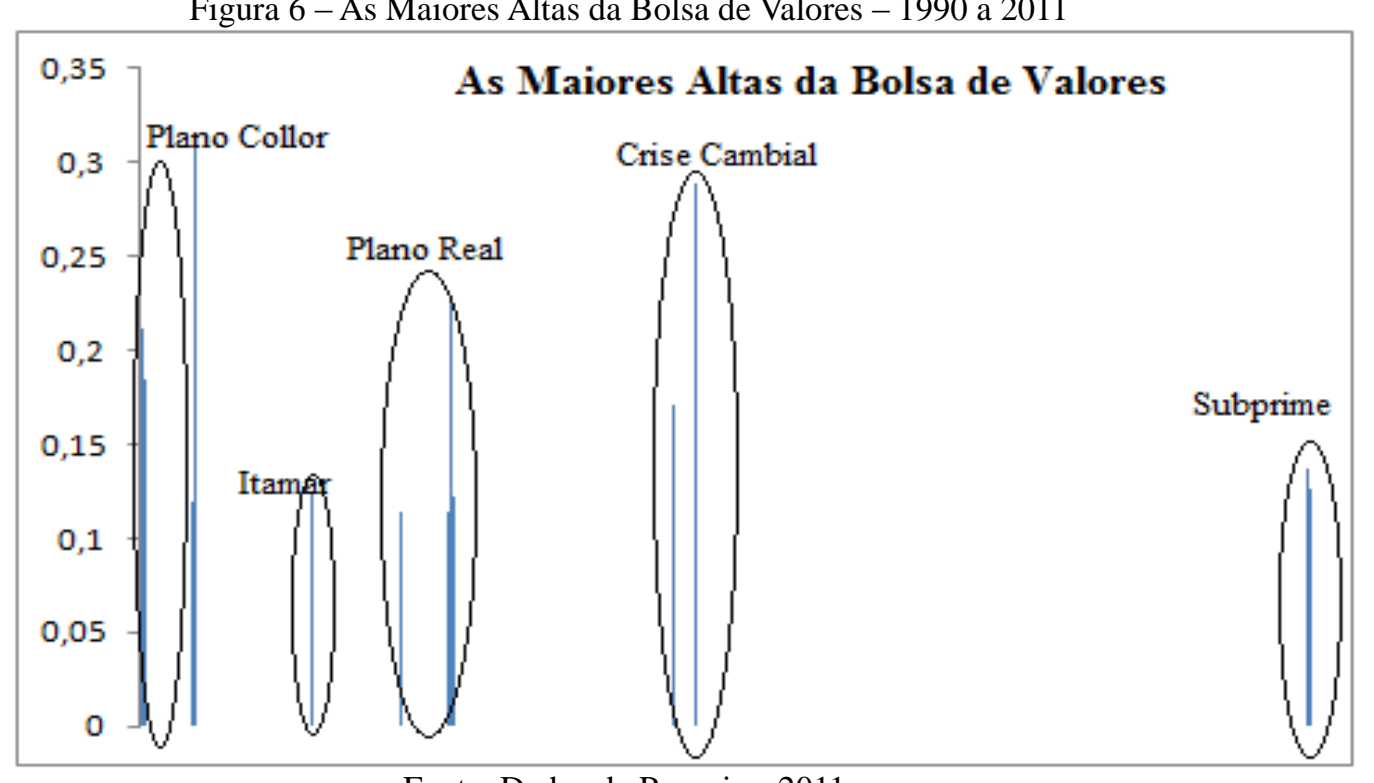

Fonte: Dados da Pesquisa, 2011 
A figura 7 corresponde a uma junção entre as figuras 5 e 6 . Ou seja, apresenta-se as maiores altas e as maiores quedas da bolsa de valores desde 1991. Cinco momentos são destacados, sendo um deles político (crise do final do governo Collor) e três referentes a problemas internos econômicos (Plano Collor, implantação do Real e crise cambial). É interessante notar que somente um dos eventos é externo ao país: a crise financeira de 2008. Neste momento, a bolsa de valores brasileira já possuía um grande fluxo de investimento estrangeiro. Assim, o mercado acionário era mais susceptível aos choques externos.

Figura 7 - As Maiores Altas e as Maiores Baixas da Bolsa de Valores - 1990 a 2011

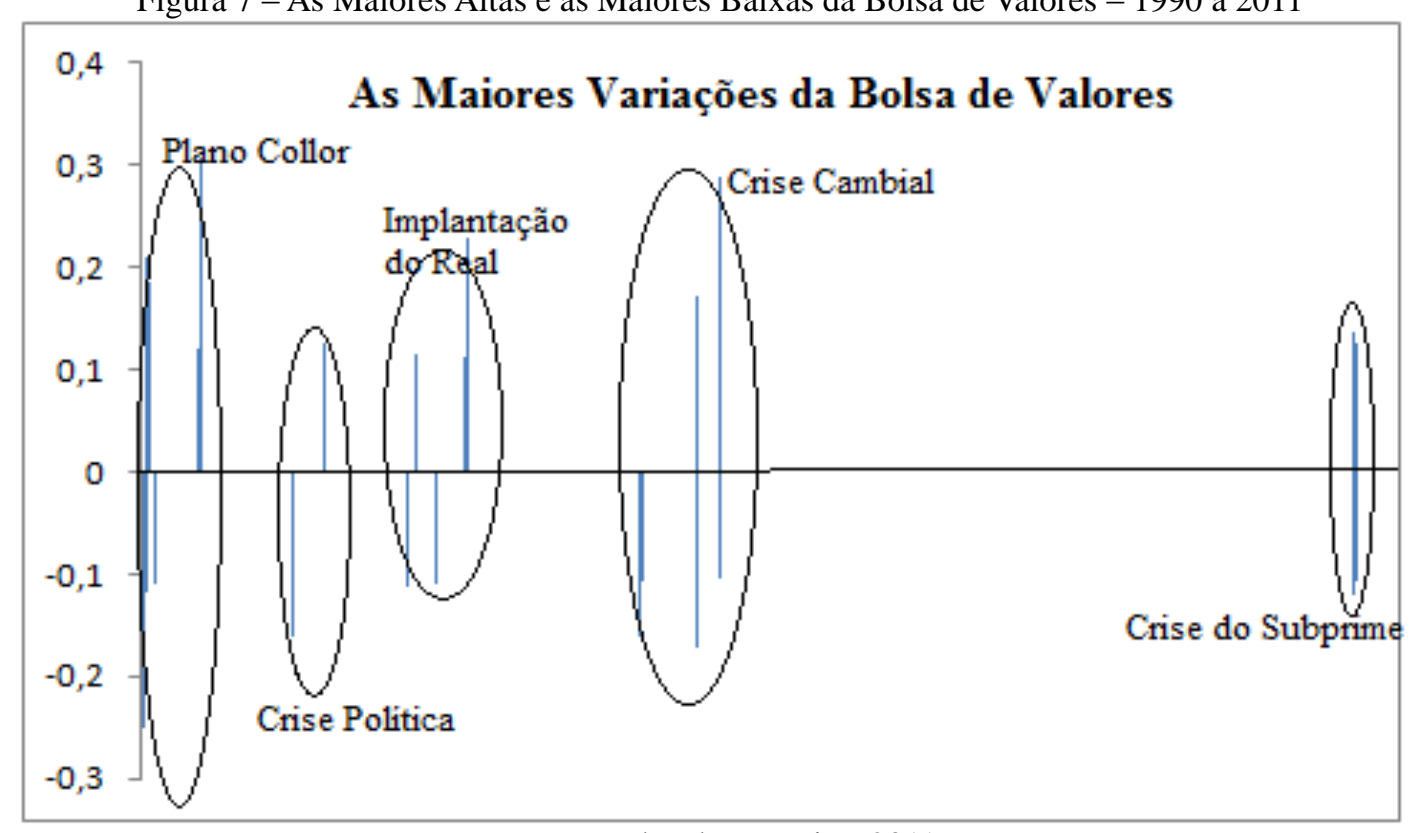

Fonte: Dados da Pesquisa, 2011.

Outro aspecto crucial da pesquisa diz respeito à coincidência dos períodos de maiores altas e maiores baixas. Assim, a mesma crise que provoca uma queda expressiva na bolsa também é responsável por um aumento substancial na rentabilidade do mercado. Isto corresponde exatamente à questão da volatilidade do mercado em situações de crises.

\section{CONSIDERAÇÕES FINAIS}

O objetivo da pesquisa foi averiguar o impacto da notícia no mercado de ações. Essa abordagem ocorreu analisando as maiores altas e as maiores baixas ocorridas no mercado acionário brasileiro no período de 1990 a 2011.

Em geral este mercado possui como característica a elevada volatilidade e o fato de refletir os acontecimentos ocorridos na política, economia e sociedade. Como o aumento na rapidez do fluxo da informação, o mercado tende a refletir, rapidamente, estes fatos. O que se observa é que além dos movimentos de alta e baixa, registrados diariamente, como consequência do ambiente onde atuam as empresas que possuem as 
ações negociadas na bolsa, existem situações onde o mercado reage de maneira extremada, com elevadas altas e baixas.

A análise da história do mercado acionário brasileiro nos últimos anos revelou que existem alguns fatores que "movem" o preço da ação. Nos primeiros anos da amostra nota-se a preponderância dos fatores internos; nos últimos anos, os fatores externos destacam-se, em razão do aumento dos investimentos estrangeiros na bolsa de valores.

Outro aspecto a ser destacado é o fato de que os motivos que geram as maiores quedas na bolsa de valores também são, essencialmente, os mesmos que justificam as maiores altas. Estes momentos produzem um elevado "nervosismo" no mercado, provocando um aumento na volatilidade dos preços das ações.

A estabilização da economia, ocorrida a partir do plano Real, aparentemente mudou o foco de volatilidade do mercado de capitais brasileiro. Uma pesquisa mais aprofundada, usando informações de períodos anteriores a 1990, poderia corroborar esta conclusão. Este é um desafio que está à espera dos pesquisadores.

\section{REFERENCIAS}

CAMPBELL, John et al. The Econometrics of Financial Markets. Princeton: Princeton University Press, 1997.

CUTLER, David M.; PORTEBA, James M.; SUMMERS, Lawrence H. What moves stock prices? Journal of Portifolio Management, Primavera 1989, 15, 3; ABI/ INFORM Global

FAMA, Eugene F.;FRENCH, Kenneth R., "The Cross-Section of Expected Stock Returns", The Journal of Finance, Vol.XLVII, N.2, Jun. 1992.

FAMA, Eugene; FRENCH, Kenneth Common factors in the serial correlation of stock returns, Working paper, Graduate School of Business, University of Chicago, October, 1986

FOLHA DE SÃO PAULO. Diversos números. Disponível em http://acervo.folha.com.br/, Acesso em 2011 e 2012.

HIRSHLEIFER, David. 2001. "Investor Psychology and Asst Pricing”, Journal of Finance 56 (4) August, 1533-1598.

MILANEZ, Daniel Yabe. Finanças Comportamentais no Brasil, Dissertação de Mestrado. São Paulo, 2003.

ROLL, Richard. Orange juice and weather. American Economic Review, v.74, n.5, p. 861-880, Dec 1984.

SHLEIFER, Andrei. 2001.Inefficient Markets: "An Introduction to Behavioral Finance" Oxford University Press Inc., New York. 
SHILLER; R. J. Do stock prices move too much to be justified by subsequent changes in dividends? American Economic Review. V. 71, n.3, june, p.421-436. 1981.

TALEB, Nassim Nicholas. A lógica do Cisne Negro Rio de Janeiro: Best Seller, 2007 THALER, Richard H., MULLAINATHAN, Sendhil. 200. "Behavioral Economics" National Bureau of Economic Research, Working Paper 7948.

"Saiba quais foram as principais crises ao longo dos últimos 40 anos" Disponível em http://www.insidernews.com.br/tudo-sobre/saiba-quais-foram-as-principais-crises-aolongo-dos-ultimos-40-anos. Acesso em: 13 de janeiro de 2012

\footnotetext{
${ }^{\mathrm{i}}$ Os autores gostariam de agradecer as contribuições de dois pareceristas anônimos, além das contribuições valiosas do editor. Naturalmente que os erros do texto são de inteira responsabilidade dos autores.

ii O número de estudos de eventos já realizados é bastante substancial. Uma pesquisa no Google Scholar com "estudo de eventos" mostrou, em de junho de 2012, 847 resultados. Isto, naturalmente, está limitado aos resultados na literatura em língua portuguesa. A referência mais usada sobre este assunto é CAMPBELL, John et al. The Econometrics of Financial Markets. Princeton: Princeton University Press, 1997.
} 